\title{
Iron (II) oxidation kinetics variability in the Atlantic Ocean and development of an improved theoretical equation
}

\author{
DAVID GONZÁLEZ-SANTANA ${ }^{1}$, MELCHOR GONZALEZ- \\ DAVILA $^{2}$, MAEVE LOHAN ${ }^{3}$, LISE ARTIGUE ${ }^{4}$, HÉLÈNE \\ PLANQUETTE $^{5}$, GERALDINE SARTHOU ${ }^{5}$, ALESSANDRO \\ TAGLIABUE $^{6}$ AND PROF. J. MAGDALENA SANTANA- \\ CASIANO $^{7}$ \\ ${ }^{1}$ CNRS, Univ Brest, LEMAR \\ ${ }^{2}$ Universidad de Las Palmas de Gran Canaria \\ ${ }^{3}$ University of Southamtpon \\ ${ }^{4}$ LEGOS (Laboratoire d'Etudes en Géophysique et \\ Océanographie Spatiales) \\ ${ }^{5}$ University Brest, CNRS, IRS \\ ${ }^{6}$ University of Liverpool \\ ${ }^{7}$ Universidad de Las Palmas de Gran Canaria (ULPGC) \\ Presenting Author: david.gonzalezsantana@univ-brest.fr
}

One of the recently recognized main sources of iron to the deep ocean inventory is the hydrothermal activity associated with mid-ocean ridges. Little is known about the oxidation kinetics of iron (II) within these environments, especially the dependence on physico-chemical parameters such as temperature (T), $\mathrm{pH}$, particle size-fractionation and the effect of organic matter.

During the GEOTRACES GA13 section cruise (FRidge), the iron (II) oxidation rate constants at six hydrothermal vent sites (Menez Gwen, Lucky Strike, Rainbow, Lost City, Broken Spur and TAG) along the Mid-Atlantic Ridge were investigated, revealing high variability. Further iron (II) oxidation rate constant analysis experiments from multiple stations revealed that the presence of organic ligands and colloidal size particles delayed the oxidation process, while not affecting the overall $\mathrm{pH}$ dependency.

In order to extend the multiparametric equation of the iron (II) oxidation rate constants, a set of selected samples was analysed across a range of temperatures between 2 and $25^{\circ} \mathrm{C}$ and of $\mathrm{pH}$ between 7 and 8 . The new equation covers a larger range of temperatures than previous published equations and provides consistently better statistical results, thus improving its applicability for global biogeochemical models. 